\title{
O ESTADO DE DIREITO E OS DIREITOS DA PERSONALIDADE (")
}

\author{
JOSÉ LAMARTINE CORRÊA DE OLIVEIRA • \\ FRANCISCO JOSÉ FERREIRA MUNIZ (**) \\ "Muitos milagres há, mas ○ \\ mais portentoso é o homem".
}

Sófocles

1. Dois exemplos históricos de passagem do típico para o atípico. Por motivos de natureza puramente de método de exposição - e que melhor serão entendidos no curso de trabalho - gostaríamos de começar pela análise de como, em dois sistemas jurídicos distintos, a previsão tipificada em lei de casos específicos de lesão aos direitos da personalidade terminou por ser sentida como insuficiente pela consciência jurídica, levando os tribunais a construirem, com o auxílio de normas constitucionais, uma noção mais ampla e geral, que servisse de fundamento à proteção dos direitos de personalidade não previstos pela especificação legislativa. Esta introdução servirá ao mesmo tempo para salientar a importância crescente que vem sendo reconhecida ao problema dos assim chamados direitos da personalidade em todos os países civilizados.

O primeiro exemplo é o da Alemanha. O BGB foi promulgado em 18 de agosto de 1896, entrando em vigor a $1 .^{\circ}$ de janeiro de 1900. A época de sua promulgação coincide portanto com o período em que se consolidava a ainda recente unificação da Alemanha, tendo por isso mesmo, como não poderia deixar de ser, sob o influxo da Escola Histórica, tido grande influência em seu conteúdo e método - Direito Romano, tal como pesquisado pelos romanistas da Escola Histórica, o antigo Direito germânico, bem como os códigos dos antigos Estados alemães. A Alemanha não completara a transição de Estado agrário para Estado industrial e, em conseqüência, a pressão das massas operárias não se fizera sentir de modo a provocar o surgimento do Direito Trabalhista. Código destinado às necessidades da

(*) Tese apresentada à VII Conferência Nacional da Ordem dos Advogados do Brasil.

$\left.{ }^{* *}\right)$ Professores de Direito Civil na U.F.Pr. e advogados em Curitiba. 
classe média, a preocupação dominante de seus autores foi a regulamentação das relações de natureza patrimonial. De outro lado, a influência da pandectística fez do BGB um código em que a preocupação de extrair deduções, divisões e subdivisões, em obediência a uma lógica abstrato-dedutiva, deixa muitas vezes em segundo plano a preocupação com a fidelidade à natureza das coisas ou com a justiça e a equidade ou com a adequação às finalidades econômicas. Não obstante, deve-se observar que; sem embargo de tudo isso (e de sua linguagem que eminente autor alemão ccnsidera seca e artificial, dada a preocupação dominante com a exatidão técnica), o caráter generalizador e abstratizador da técnica legislativa do BGB permitiu talvez ao grande Código sua extraordinária sobrevivência em meio às vicissitudes histórico-políticas por que passou a Nação alemã, sendo - Código que vigorou no tempo do Império, sob a República de Weimar, sob a ditadura nazista e, após a divisão da Alemanha, quer na Alemanha Federal sob o regime da Lei Fundamental de 1949 e a Social-Democracia; quer na República Democrática Alemã, até data recente (recentemente entrou em vigor na RDA $\circ$ novo Zivilgesetzbuch, ZGB). (1)

O fato, porém, é que, no ponto que nos vai interessar de modo particular, o BGB representou alargamento da tipificação da tutela da personalidade. Seu $\S 823$, al. 1, considera obrigado a indenizar o dano quem, dolosa cu culposamente, lesa, de modo contrário ao direito, a vida, a integridade corporal, a saúde e a liberdade. Essa enumeração de quatro bens da vida equiparados a direitos subjetivos para a hipótese de sua lesão $\left({ }^{2}\right)$, representa, através da inclusão da menção à liberdade, entendida aqui em sentido amp!o e não meramente privatístico, expressão de uma preocupação de defesa do homem em face do Estado. Trata-se, portanto, de técnica em que não há ainda a rígida separação entre os aspectos privatísticos e os publicísticos (com a exclusão destes do texto dos códigos), que caracterizaria. fase pcsterior da História do Direito, antes que se chegasse à atual fase, de crise do dualismo público-privado. (3) Essa tutela, porém, da personalidade, é concedida em perspectiva que Perlingieri considerou "estranhamente patrimonial", eis que "à violação de bem que pertence à categoria do ser e à própria existência do homem é contraposta sanção que não diz respeito ao ser, mas ao ter". ( $\left.{ }^{4}\right)$

1 Karl LARENZ, "Allgemeiner Teil des deutschen bürgerlichen Rechts", Beck, Munich, 1967, págs. 11, 23. Do mesmo autor "Einführung" à edição do BGB do Deutscher Taschenbuch Verlag, Munich, 1973, págs. 11-14.

2. Karl LARENZ, "Allgemeiner Teil", pág. 165.

3 Pietro PERLINGIERI, "La personalità umana nell'ordinamento giuridico", Università degli Studi di. Camerino, vol..3, Jovene edit:r, Cameino, 1972, págs. 41, 42, 11 e 12.

4 İlem, pág. 42. 
A verdade, porém, é que essa enumeração limitativa viria a revelar-se amplamente insuficiente. Com efeito, embora, em comparação com situações legislativas anteriores, tenha havido um alargamento, como já foi dito, a própria técnica de enumeração tipificante leva a uma limitação na tutela da personaildade. Os progressos da técnica moderna tornaram possíveis agressões à esfera privada da vida humana que não poderiam ter sido previstas pelo legislador do fim do século XIX. Pense-se apenas, e para exemplificar, em toda a aparelhagem de gravação, de filmagem, de fotografia que pcde captar som e imagem de modo a caracterizar interferências injustificadas na vida pessoal. Tudo isso levou o Tribunal Federal criado pela Lei Fundamental de 1949 (Bundesgerichtshof, por abreviação BGH) a, rompendo com a jurisprudência do antigo Tribunal do Reich, criar, a partir de 1954, a doutrina segundo a qual existiria um assim chamado direito geral de personalidade (allgemeines Persönlichkeitsrecht). Com isso, a jurisprudência alemã retomava com renovado vigor posição que era a de Gierke e de Egger e que fora abandonada, sob o influxo da técnica tipificadora do BGB. Fundamento invocado pelo Tribunal Federal para a nova jurisprudência foi o princípio consagrado pelos atrigos $1 .^{\circ}$ e $2 .^{\circ}$ da Lei Fundamental (Grundgesetz), nome dado à Ccnstituição de 1949, também conhecida como Constituição de Bonn. Segundo o art. 1. ${ }^{\circ}$, "a dignidade do ser humano é intangível. Respeitá-la e protegê-la é dever de todo poder estatal. O povo alemão reconhece por conseguinte os invioláveis e inalienáveis direitos do homem ccmo fundamento da comunidade humana, da paz e da justiça no mundo. Os direitos fundamentais que seguem vinculam o legislador, o Poder Executivo e o Judiciário como Direito imediatamente vigente". O art. $2 .^{\circ}$ assim reza: "Todos têm direito ao livre desenvolvimento da própria perscnalidade, contanto que não violem os direitos alheios. e não transgridam a ordem constitucional ou a lei moral. Todos têm direito à vida e à incolumidade física. A liberdade da pessoa é inviolável. Esses direitos só podem ser limitados ccm base em lei". Discute-se o Tribunal Federal realmente deduziu diretamente do texto constitucional a doutrina do direito geral da personalidade ou se, em verdade. teria efetuado verdadeira criação judicial do Direito. No fundc, a discussão não tem para nós maior relevância quer por corresponder a doutrina do direito geral da personalidade, como observa Esser, a uma ampliação da proteção da personalidade, para além das possibilidades abertas pelo BGB, sentida unanimemente como indispensável, quer porque, como anota Larenz, tal criação encontra justificativa, em última análise, em um princípio ético-jurídico declarado com especial intensidade na Constituição( $\left.{ }^{5}\right)$.

5 Josef ESSER, "Schuldrecht", vol. II, ed. Müller, Karlshure, 1971, págs. 400 e 401; Giovani PUGLIESE, "Alcuni problemi sui diritti della personalità", (Giornate giuridiche italo-jugus- 
No que diz respeito à Alemanha Oriental (República Democrática Alemã), seu novo Código Civil, de 1975, contém uma cláusula geral que reconhece direito geral de personalidade. Tal regra, como observa o professor Roggemann, representa, como texto legislado, um avanço em relação ao $B G B$, embora o texto em si seja mais modesto na proteção concedida do que o âmbito de proteção dispensado pela jurisprudência dos tribunais da Alemanha Federal. $\left({ }^{6}\right)$

O segundo exemplo é o do Direito italiano. O Codice Civile vem à luz em 1942, em pleno domínio do fascismo. Escassas são suas normas destinadas a regular os direitos da pessoa física. Depois dos artigos iniciais, que definem a capacidade de direito e a de fato, a maioridade, a comcriência (artigos 1-4), edita o Codice norma destinada a limitar os atos de disposição do próprio corpo (artigo 5), o direito ao nome e ao pseudônimo (artigos 6-9) e o direito à própria imagem (artigo 10). Por isso mesmo, Tucci teve ocasião de observar que, se abstrairmos do artigo 5, de escassa importância inovadora, pouco resta. A tutela do direito ao nome já existia no $B G B$, no $\S 12$. Note-se, por ser circunstância extremamente significativa, que contra esse modesto elenco normativo, no curso dos trabalhos preparatórios, se haviam insurgido os pregoeiros de uma rigorosa concepção fascista do Estado: segundo os fascistas, bastaria a tutela publicística dos direitos da pessoa, sendo corpo estranho no sistema a tutela de natureza privatística. $\left(^{7}\right)$ Note-se como a concepção totalitária do Estado utiliza em seu benefício a separação rígida entre Direito Público e Privado. No âmbito do Direito Civil nasceu a defesa do ser humano contra o poder do Esłado. Mas, como observa Tucci, o século XIX conheceu um processo de progressivo esvaziamento dos Códigos Civis em relação ao primitivo conteúdo de defesa dos direitos individuais do Direito Privado. Tucci faz, nesse sentido, o contraste entre o Código austríaco, jusnaturalista, e o BGB, "que conclui o grandioso movimento das codificações européias". ( $\left.{ }^{8}\right)$ E curioso notar que Perlingieri chega, por outros vias, a conclusão análoga, mostrando que, tanto o BGB, quanto o Codice Civile de 1942 representam códigos de uma fase histórica em que se efetua a separação entre a proteção dos direitos políticos do ser humano e a dos aspectos puramente privatísticos da

lave), Guiffré, Milão, 1964, pág. 5; Frederico de CASTRO, "Los llamados derechos de la personalidade", in "Anuario de Derecho Civil", tomo XII, fasc. IV, 1958, pág. 1252 e nota 62; Giorgio GIAMPICCOLO, “La tutela giuridica della persona umana e il c.d. diritto alla riservatezza", in "Riv. Trim., dir. proc. civ.", 1958, pág. 470; Karl LARENZ, "El derecho general de la personalidad en la jurisprudência alemana", in Revista de derecho privado, 1963, pág. 644 .

6 Herwig ROGGEMANN, "Das Zivilgesetzbuch der DDR von 1975", in Neue Juristische Wochenschrift. 1976, cad. 10, pág. 395.

7 Giuseppe TUCCI, “Il danno ingiusto", Jovene ed., Napóles, 1970, pág. 152.

8 Idem, pág. 153. 
tutela da personalidade humana, excluída a primeira dos Códigos $\mathrm{Ci}$ vis. $\left(^{9}\right)$ Com a redemocratização iłaliana, a Constituição de 1947 abriria novos horizcntes. Seu artigo $2 .^{\circ}$ afirma reconhecer e garantir a República "os direitos invioláveis do homem, seja como indivíduo, seja nas formações sociais em que se desenvo've sua personalidade" e exigir (a República) "o cumprimento dos deveres inderrogáveis de solidariedade pclítica, econôm ca e social". O artigo $3 .^{\circ}$ prevê a igualdade em dignidade e perante a lei entre todos os homens e assinala como objetivo da Repúb.ica a remoção de "obstáculos de ordem econômica e social que, limitando de fato a liberdade e a igualdade dos cidadãos, impedem c pleno desenvolvmento da pessoa humana e a efetiva participação de todos os trabalhadores na organização política, econômica e social do país". Esses dois textos constitucionais - o artigo $2 .^{\circ}$ e a al. $2 .^{\circ}$ do artigo $3 .^{\circ}$ - ccnstituem a base, na ltália, do surgimento, em sede doutrinária e jurisprudencial, da concepção de um direito geral da personalidade, de um único direito da personalidade. O artigo $2 .^{\circ}$ é mais especialmente referido pelos autores com base constitucional de tais idéias. Não é relevante aqui aprcfundar qualquer análise dogmática tendente a demonstrar a insuficiência ou o superamento da doutrina do direito geral da personliadade. O que importa salientar é ter ela significado a necessária reação contra a concepção fragmentária que só admitia tutela dos direitos de personalidade tipicamente previstos. $\left({ }^{10}\right)$

Que sentido tem, no conjunto deste trabalho, a análise dos dois exemplos que vem de ser feita? Que lições podem ser extraídas, que permitam dar um passo em direção a uma segunda etapa de exposição?

Extrairemos duas lições fundamentais, em plano dcutrinário, e de cada uma delas será possível retirar uma lição no plano técn'cojurídico.

Em primeiro lugar, a experiência dessas duas Nações demonstra - caráter absolutamente insatisfatório de uma proteção fracionada, fragmentária, de direitos da personalidade, enumerados e tipificados. A tipclogia que se pretende exaustiva não exaure a realidade e camufla o sentido único de toda a problemática. Dessa primeira lição, pode ser extraído o corolário da extrema dificuldade de uma adequa-

9 P.PERLINGIERI, op. cit. págs. 41, 44.

10 Franco BRICOLA, "Prospettive e limiti della tutela penale della riservatezza", in "Rivista italiana di Diritto e Procedura Penale, Giuffré, Milão, fasc. 4, outubro-dezembro, 1967, págs. 1094 - 1095. Giorgio GIAMPICCOLO, cp. cit., págs. 469 e 471; P. PERLINGIERI, op. cit., págs. 183, 188. Veja-se referência jurisprudencial de forma a demonstrar o reconhecimento, pela Corte di Cassazione, de um "complexo de direito da persona idade", no trabalho já citado de BRICOLA, pág. 1095, nota 63. 
da tutela jurisdicional da personaildade humana sem a introdução no Direito legislado de uma cláusula geral apta a, através da concreção, fornecer a base de uma jurisprudência coerente, mas suficientemente sensível para a so'ução das mais variadas hipóteses de lesão aos dire:tos da personalidade. $\left.{ }^{11}\right)$ Só assim encontra o Direito justificação em termos de uma vinculação com a vida real.

Em segundo lugar, o exemplo serve para demonstrar a impossibilidade de uma construção doutrinária que busque construir essa cláusula geral e se feche dentro do campo do Direito Civil, ignorando os fundamentais princípios que asseguram o respeito à dignidade da pessoa humana. No plano doutrinário, isso significa que só através do entendimento da ordem jurídica como um todo, que tem por base uma hierarquia de valores, dentro da qual ocupa lugar primacial a noção de que o ser humano é pessoa, dotada de inalienável e inviolável dignidade, é possível dar à noção de direitos da personalidade toda a sua real amplitude. Para tal, é necessário vincular a noção de direiłos da personaildade à noção de direitos do homem. É verdade que a doutrina distingue tradicionalmente as duas noções. A distinção, porém costuma assentar em dois pontos de vista principais. De um lado, a dicotomia patrimonial - não patrimonial. Assim, o direito de propriedade seria direito do homem mas não o direito da personalidade. Para o ponto que nos interessa, essa distinção é irrelevante. Pois o que procuramos demonstrar é que a tutela jurídica da personalidade humana exige a aceitação de noções prévias e fundamentais de um modo especial, a noção de pessoa humana - que estão na base da noção de direitos do homem e que servem de guia diretiva - como os dois exemplos demonstraram - para a concretização das várias aplicações da noção de direito geral da personalidade e para a própria fcrmulação dessa noção. De resto, mesmo no plano da noção estrita de direitos da personalidade, afirma-se cada vez mais a tendência no sentido de um superamento da dicotomia patrimonial - não patrimonial, de modo a abranger a noção de direito da personalidade direitos de indiscutíveis conseqüências patrimoniais, ccmo por exemplo o direito ao trabalho. ${ }^{(12)}$ De resto, a própria pretensão de ressarcimento do dano, (embora não seja a única que pode emergir da lesão ao direito da personalidade) cuja admissão é fundamental

1) Nesse sentido, salientando a importância, nesse particular, de um m-todo de concreção, sensível e sem o mecanismo de uma simples subsunção do caso específico à norma geral, abstrata, Fritz OSSENBÜHL, "Die Interpretation der Grundrechte in der Rechtsprechung des Bundesverfassungsgerichts", in "Neue Juristische W:chenschrift", cad. 46, 1976, pág. 2105.

12 Giovanni PUGLIESI, "Aspetti civilistici della tutela del diritto della personalità nell'ordinamento italiano", in "Alcuni problemi sui diritti della personalità", Giuffré, Milão, 1964, pág. 12. Também nesse sentido, Henri, Léon e Jean MAZEAUD, "Leçons de Droit Civil", tomo 1.0, Montchrestiens, Paris, 1955, pág. 636, n.0 641: "sucedâneo do direito à vida, tem seu lugar entre os direitos da personalidade". 
para que não resulte platônica a tutela dos direitos da personalidade, demonstra a impossibilidade de aferramento à rígida separação entre o patrimonial e o não patrimonial. É a superação dessa visão que explica toda a evolução sofrida pelo Direito em matéria de dano moral. De outro lado, a distinção direitos do homem - direitos da personalidade é habitualmente assentada sobre a distinção públicoprivado. Assim, segundo os Mazeaud, quando se examinam os direitos da personalidade, na maior parte das vezes, estaria o jurista diante dos mesmos direitos do homem vistos sob o ângulo das relações entre particulares; tratar-se-ia "de defender esses direitos não mais contra o poder da autoridade, mas contra os atentados dos particulares". $\left.{ }^{13}\right)$ Mesmo vista sob tal ângulo, tal distinção não pode ser rígida. Existe $\circ$ princípio da responsabilidade civil do Estado, que interessa ao Direito Público e ao Direito Civil, e essa responsabilidade pode surgir de uma lesão a direito da personalidade. No fundo, e sem enfrentar aqui o problema da distinção púb.ico-privado, o que estamos procurando sustentar é a necessidade de um superamento da separação entre duas concepções unilaterais do direito da personalidade, uma exclusivamente privatística e outra exclusivamente publicística. $\left({ }^{14}\right)$

Daí decorre a importância de que o prcblema seja analisado à luz dos grandes princípios constitucionais, que fornecem inclusive critérios de valor e que devem inspirar uma releitura do próprio texto da lei ordinária à luz dessa inspiração global que a Constituição acoIhe. $\left({ }^{15}\right)$

O que vem de ser dito - apesar da utilização do exemplo alemão e do italiano - não tem valor restrito tão só aos ordenamentos de Direito Privado que se tenham limitado a uma tipificação de casos específicos de direitos da personalidade.

Assim, o Código Civil português, de novembro de i966, contém, ao lado de normas sobre os direitos típicos de personalidade, uma cláusula geral, a do artigo 70, alínea 1: 'A lei protege os indivíduos contra qualquer ofensa ilícita ou ameaça de ofensa à sua personalidade física ou moral". É evidente que essa norma há de ser relida à luz da nova Constituição portuguesa, de 2 de abril de 1976, segundo a qual (artigo 1.०), "Portugal é uma República soberana, baseada na dignidade da pessoa humana e na vontade popular e empenhada na sua transformação numa sociedade sem classes". A primeira parte do artigo ressalta a dignidade da pessoa humana como um dos dois valores básicos do ordenamento português.

13 MAZEAUd, op. cit. pág. 629, n.0 624.

14 Nesse sentido, P. PERLINGIERI, op. cit. pág. 15.

15 Veja-se PERLINGIERI, cp. cit., págs. 15-16, 18-19 e OSSENBUHL, op. cit., págs. 2101/2103. 
Assim, o Código Civil francês nasce sem conter qualquer referência aos direitos da personalidade. Mas a evolução operou-se. A Constituição de 1958 contém em seu preâmbulo expressa adesão aos princípios da Declaração dos Direitos do Homem de 1789 e o Conselho constitucional considerou os princípios decorrentes da Declaração invocada pelo Preâmbulo da Constituição como vinculantes para o legislador, em decisão de 1971. De outra parte, a aceitação ampla pela jurisprudência do princípio da proteção aos direitos da personalidade já encontrou expressão legislativa: a lei 70-643, de 17 de ju'ho de 1970, introduziu no velho Código o novo artigo 9.': que as:egura a todes 0 direito ao respeito de sua vida privada. $\left({ }^{16}\right)$

E a Suiça, que tem em seu Código uma cláusula geral (o famoso artigo 28), reconhece, por meio da doutrina, "um direito geral da personalidade". (17) Um outro autor suiço assinala de modo expressivo: "A cada ordem jurídica ccrresponde uma certa escala de valores, e é ela, em definitivo, que fornece a chave dos mistérios do atrigo 28 do CCS". O mesmo autor, em observação de validade universal, assinala: "... os direitos da personalidade feriam pouco valor em um Estado que sacrificasse as liberdades individuais ou que se mcstrasse incapaz de assegurar a ordem pública". ${ }^{18}$ )

2. Direiłos da perscnalidade, direios do homem e a noção de pessoa. Na parte anterior deste trabalho, demonstramos a impossibilidade de uma visão puramente privatística de direitos da personalidade que desvinculasse esse capítulo do Direito Civil da categoria ampla dos direitos do Homem. Damos agora um passo à frente, para demonstrar que uma e outra categoria (direitos da personalidade e direitos do Homem) só podem ser entendidas à luz de uma noção de pessca que supere o esvaziamento a que tal noção foi submetida pela carga histórica de uma educação jurídica positivista a pesar sobre sucessivas gerações de cu'tores do Direito.

$\mathrm{Na}$ verdade, só uma noção pré-normativa de pessoa permite entender toda a riqueza da noção e a amplitude de suas possíveis aplicações em matéria jurídica. Um contraste útil como visualização pode ser estabelecido entre a nç̧ão clássica de Boetio, que via na pessoa a rationalis naiurae individua substanỉia e a concepção de Ke'sen, destinada a reduzir a pessoa a mero ponioo de imputação, Zurechnugispunkt. Na primeira visão, expressão do jusnaturalismo cristão, o ser humano é reconhecido ccmo indivíduo, mas não apenas

16 Veja-se, a respeito, Alex WEILL, "Drcif Civil", tomo I, vol. 2.0, Dalloz, Paris, 1972, pág. 20.

17 SIMONIUS, "Rappert sui le probleme en Droit suisse", in "Travaux de l'Association Henri Capitant", Dalloz, Paris, 1974, pág. 306.

18 Jacques - Michel GRUSSEN, "Les personnes physiques", in "Traité de Droit Suisse", tomo 11, 2, Edições Universitárias de Friburgo, Suiça, 1974, pág. 79. Nisso o grifo. 
indivíduo: substância também, isto é, ser que existe por si mesmo; e de natureza racional. Dessa noção decorre a dignidade da pessoa humana, dado anterior e superior à ordem legislada. E exatamente por que a pessoa jurídica (as asscciações, sociedades, fundações, o próprio Estado) não é ser que exista por si mesmo, mas através dos homens e em função destes, que a pessoa jurídica, embora não exprima uma ficção, mas uma realidade, é pessoa por analogia ao ser humano e não é portanto dotada da dignidade essencial reconhecida ao ser humano. Em uma visão positivista, normativista, formalista, da pessoa e da própria ordem jurídica, ao contrário, termina-se por reduzir a noção de pessoa a um centro de imputação de direitos e deveres, e a atribuir-se sentido idêntico às noções de pessoa e de sujeito de direitos. Em uma visão personalista, o ordenamento jurídico, ao construir dentro do sistema, a noção de personalidade, assume uma noção prénormativa, a noção de pessca humana, faz de tal noção uma noção aceita pela ordem positiva. Não a assume nem a aceita porém no mesmo sentido de pura aceitação da realidade externa com que aceita e assume a qualidade de objetos, de coisas, que têm uma árvore ou um animal. É que, no caso do ser humano, o dado pré-existente à ordem legislada não é um dado apenas ontológico, que radique no plano do ser; ele é também axiológico. E ser e valor estão intimamente ligados, em síntese indissolúvel, eis que o valor está, no caso, inserido no ser. $O$ homem vale, tem a excepcional e primacial dignidade de que estamos a falar, porque é. E é inconcebível que um ser humano seja sem valer. Por isso mesmo, a personalidade é uma noção insuscetível de gradações ou restrições. A capacidade de direito, ao contrário, pode sofrer restrições ou limitações por parte da ordem positiva. Como a noção de personalidade só pode ser construída, em uma ordem jurídica digna desse nome, sobre a afirmação da fundamental dignidade de todos os seres humanos, daí decorre evidente corolário de igualdade essencial entre tcdos os homens. E daí decorre, também, indispensável atitude crítica do jurista em face do ordenamento no caso de restrições ou limitações à capacidade dos seres humanos que firam esse princípio de igualdade. Daí decorre, ainda, o caráter chocante que tem a afirmativa, tão corrente em juristas de formação pcsitivista, e segundo a qual a prova de um caráter puramente positivo da noção de pessoa seria dada pela escravidão do mundo antigo. A escravidão demonstra apenas a insuficiente penetração em determinada ordem jurídica positiva da noção pré-normativa que acabamos de sustentar. $\left({ }^{19}\right)$

19 No sentido essencial do que vem dito no texto: FEDERICO DE CASTRO Y BRAVO, "Compendio de Derecho Civil", Madrid, 1970, pág. 162-163, KARL LARENZ, Allg. Teil, págs. 57-61, do mesmo autor "Methodenlehre der Rechtswissenschaft", Springer, Berlim-Heidelberg. New York, 1975, págs. 436-437 (3.a ed. alemã); na edição. espanhola, "Metodolegia 
Ao defendermos uma noção personalista do Direito, não estamos sustentando uma concepção individualista da sociedade, como ao analista desinformado e superficial poderia parecer. Conscientes de que só a noção substancial de pessoa confere sentido e dignidade ao Direito, e de que só tal noção permite uma visão crítica e valorativa dos diferentes ordenamentos jurídicos, não enxergamos o ser humano de maneira abstrata, mas em sua inserção concreta na História e na sociedade. Em uma visão personalista, o ser humano não é visto como átomo isolado em face do Estado nem em visão competitiva de ser contra o outro; mas, como ser como o outro.

$\mathrm{Na}$ verdade, os autores deste trabalho não escondem seu profundo repúdio ao positivismo jurídico. Não se negam a admitir que - na medida em que entendem necessário distinguir, dentre os várics ordenamentos jurídicos positivos, entre os que realizam de modo mais fiel ou mais infiel os valores da pessoa humana - que com isso é feito ape'o a valores superiores ao Direito legislado. Tratar-se-á de um "retorno" ao Direito Natural? Não sendo este o local adequado para um aprcfundamento do tema, não nos furtamos a reconhecer que um certo jusnaturalismo está presente na inspiração deste trabaIho. Salientamos, porém, que não se trata do jusnaturalismo racionalista do iluminismo, que desconhece a inserção do Homem na História. Já foi muitas vezes repetido que, ao contrário da concepção de Grotius ou da de Pufendorff, a própria noção de lex naturalis, no pensamento de Santo Tomás de Aquino estava longe de atribuir à lei natural qualquer caráter de sistema capaz de chegar a normas minudentes. O pensamento jusnaturalista mais moderno está também muito lcnge de qualquer concepção de sistema perfeito e acabado. Várias são as intuições fundamentais que, em vários autores, expressam essa busca de princípios superiores à ordem jurídica positiva, mas que, apesar de tudo, sofrem o proce:so de encarnação histórica. Rénard, ao imaginar seu Direito nałural de conreúdo progressivo, queria $\mathrm{ccm}$ isso frisar a circunstância de que a consciência ética da humanidade iria, de modo progressivo, ao longo da História, refinando e ampliando suas exigências éticas em face da ordem jurídica positiva. De sua parte, Arthur Kaufmann, utilizando a distinção entre Direito Natural e Lei Natural (e:ta é que seria composta de princípios imutáveis e supratemporais e bastante gerais e abstratos) vê no Direitc Natural algo que "não é estático mas de natureza sempre dinâmica: deve continuamente ser realizado de novo de modo a atingir

de la Ciencia del Derecho", ed. Ariel, Barcelona, 1966, págs. $372-374$ (tradução da ed. alemã de 1960); ORLANDO DE CARVALHO, "Les droits de I'homme dans le droit civil portugais", in "Boletim da Faculdade de Direito", vol. XLIX, Coimbra, 1973, págs. 7 e seguintes. 
a si mesmo; não é direito já feito, mas direito em contínuo devir". $\left({ }^{20}\right)$ Não é relevante aqui empreender uma análise de conjunto do pensamento dos autores citadcs, nem está aqui implícita qualquer aceitação da totalidade de suas teses. O que importa é salientar algumas idéias centrais. Uma delas é a do lugar central que em todas essas concepções assume a pessoa. Nesse sentido, apenas duas citações: a primeira diz respeito ao pensamento de Maihofer, para quem a grande pergunta que se coloca ao jurista é a pergunta sobre o sentido da existência humana e de sua crdem razoável em um mundo inumano. Para ele, em verdade, ao falar em Direito Natural, natureza das coisas ou natureza do homem, está presente a idéia de um projeto da missão essencial e histórica do homem em relação com os demais, a realizar com incessante esforço comum, dando tradução histórica à vcntade de alterar o mundo, de corrigi-lo, melhorá-lo, faze-lo digno do homem e valioso para a vida. ${ }^{21}$ A outra é de COING, para o qual "o núcleo do jusnaturalismo moderno são os direitos do homem". Estes baseiam-se na exigência moral de respeitar a dignidade do homem como pessoa moral, exigência ccntida na idéia do direito. O direito ao respeito que resulta para a continuidade jurídica e sua ordem constitui o direito geral da personalidade e é o fundamento da necessidade de reconhecer direitos subjetivos em geral. $\left({ }^{22}\right)$

$\mathrm{Na}$ verdade, a negação do direito subjetivo assinala o ccmeço do esvaziamento da noção da pessoa, em uma evolução que vai de Duguit a Kelsen, como entre nós demonstrou Mata-Machado. ( ${ }^{23}$ ) Esse conteúdo, sobre o qual o direito civil, em particular, foi e permanece construído $\left({ }^{24}\right)$, noção fundamental do direito privado contemporâneo $\left({ }^{(25}\right)$, responde a sentimentos muito profundos, dentre os quais o do respeito à pessoa humana. $\left({ }^{26}\right)$

3. Estado de direito. Chegamos agora a um ponto do trabatho em que as con:iderações anteriormente desenvolvidas permitirão

20 Arthur KAUFMANN, "La struttura ontolegica del Diritto", in "Rivista Internaziona'e di Filcsofia del Diritto", set-outubro de 1962, pág. 576. Analcgamente, Erik WOLF, "Carattere problematico e necessario della scienza del diritto", na edição italiana Giuffré. Milão, 1964, que agrupou o estudo de WOLF e um de von KIRCHMANN sob o título geral "Il valore scientifico della giurisprudenza", págs. 58-59.

21 Werner MAIHOFER, "El Derecho natural como derecho existencial", in "Ciencia Juridica", Simposio do Instituto de Filcsofia del Derecho y Sociolegia", Universidad Nacional de La Plata, La Plata, 1970, págs. 230-231.

22 Helmut COING, "Fundamentos de Filosofia del Derecho", Ariel, Barcelona, pág. 180.

23 Edgar de Godoi da MATA-MACHADO, "Contribuição ao persenalismo jurídico", Forense, Rio, 1954, págs. 50-52.

24 Jean CARBONNIER, "Droit Civil", vol. 1. Presses Universitaires de France, Paris, 1955, pág. 179.

25 G. MICHAÉLIDES-NOVAROS, "L'évolution récente de la notion de droit subjectif", in "Révue Trimestrielle de Droit Civil", abril-junho, 1966, pág. 216.

26 Alex WEILL, "Droił Civil", "Introduction", Dalloz, Paris, 1973, pág. 28. 
melhor entender a ampla ligação do tema direitos da personalidade com o tema Estado de direiło. Com efeito, vimos não ser possível conceber-se tutela efetiva dos direitos da personalidade fora do contexto de uma tutela aos direitos do homem. Veremos agora que só no Estado de direito essa tutela alcança real efetivação. E, reciprocamente, que só há Estado de direito se existir uma ordem jurídica baseada na proclamação de tais direitos e em sua efetiva proteção.

Daí decorre que de nenhum modo podemos fazer nossa uma concepção positivista de Estado de direito. O positivismo, que esvazia a noção de pessoa, e esvazia a noção de Direito, esvazia a noção de Estado de Direito. O Estado de Direito, visto pelo ângulo meramente formalista do positivismo jurídico, nada mais é que mero Estado de legalidade. Existe a preocupação de delimitar os órgãos competentes para a promulgação das leis, sua elaboração, sua aplicação. Existe, em tese, o controle da legalidade dos atos administrativos pelos tribunais. Mas os direitos individuais são apenas aqueles concedidos pelo Estado. O Direito tem por fonte o Estado. E se o Estado negar os direitos do homem, estes não mais existirão nem nada haverá a fazer senão acatar a lei. Essa concepção, levada a sua mais alta expressão, coincide com o pensamento de Kelsen. Em tal pensamento, é inconcebível o conflito entre o Estado e o Direito, ou a limitação do Estado pelo Direito, ou a subordinação da lei ao Direito. Todas essas questões são inconcebíveis em um sistema de pensamento que, assmindo uma pretensa neutralidade em face das escalas de valores, em face do mundo, da vida, do Homem, (pois todas essas questões seriam meta-jurídicas) termina, em verdade, por padecer da falta de uma opção axiológica. Não se está com isso pretendendo negar o necessário neutralismo do Estado democrático em face do pluralismo ideológico. O que se está querendo é afirmar o impossível neutralismo do Estado de direito em face dos valores fundamentais à ordem jurídica, o mais importante dos quais o da dignidade da pessoa humana. Nesse sentido, Castanheira Neves teve ocasião de precisar que o sentido puramente formal de Estado de Direito (ou seja, a noção de Estado de legalidade), que se contenta com a existência de uma forma legal e do respeito ao princípio da separação de poderes, está hoje superado. Em verdade, só se poderá falar em Estado de direito na medida em que o Estado reconheça de modo absoluto os "direitos fundamentais". ${ }^{27}$ )

Esses "direitos fundamentais", quando inseridos de modo coe-

27 A. CASTANHEIRA NEVES, "A Revolução e o Direito". Lisboa, 1976 (separata da "Revista da Ordem dos Advogados"), págs. 203-204. Quanto ao positivismo e KELSEN, veja-se Gustav RADBRUCH, "Propedentica alla Filosofia del Diritto", trad. italiana da "Vorschule", ed. Giappichelli, Turim, 1958, págs. 221-222. Sobre a noção de Estado de legalidade, veja-se MARCELO CAETANO, "Direito Constitucional", Fcrense, Rio, 1977, pág. 377, n.0 174. 
rente em Constituição calcada em concepção personalista do Direito (sem a qual, como estamos procurando demonstrar, não existe verdadeiro Estado de Direito), constituem verdadeiros princípios destinados a estabelecer uma escala fundamental de valores, centrada no reconhecimento da pessoa humana e de sua dignidade, e que deverá vincular a administração, a legislação e a jurisdição. $\left({ }^{28}\right)$. De modo que a própria tarefa de controle da constitucionalidade das leis e da legalidade e constitucionalidade dos atos administrativos há de ser inspirada por essa opção axiológica. No preciso ensinamento de Castanheira Neves, "o próprio pensamento constitucionalista se dá conta de uma juridicidade constitucional mais exigente do que aquela que se defina apenas ao nível constitucional positivo, (...) - além de que, e fundamentalmente, o estatuto constitucional traduz sobretudo a assimilação jurídica de certos valores políticos". $\left({ }^{29}\right)$ O ilustre professor de Coimbra vai, porém, ainda além. Com efeito, sabemos que o legislador não é onipotente. Sua tarefa encontra limites na natureza das coisas e nos valores superiores constituciona'mente consagrados. Na verdade, nem mesmo o constituinte é onipotente. "Pelo que se fala hoje da possível inconstilucionalidade de leis constitucionais, no reconhecimento, pois, de uma axiologia transpositiva que não está na absoluta disponibilidade do positivo constitucional ou de que não é titular sem limites o poder constituinte ${ }^{\prime \prime} .\left({ }^{30}\right)$ Na mesma linha de preocupações, entre nós, o professor Ary Flcrencio Guimarães salienta que as liberdades fundamentais da pessoa humana "especificam uma solene anterioridade dos direitos naturais e inalienáveis do homem, não decorrentes, como já se demonstrou, das normas positivas ou jurídicas ccnsagradas pelo Estado", pois que "pré-existem ao nascimento do próprio Estado". ( $\left.{ }^{31}\right)$ Só nessa dimensão é possível superar a distinção entre o mero Estado de legalidade e o Estado de direito, sem o qual não cabe falar em democracia. No dizer lapidar de Castanheira Neves, ". . a verdadeira soberania comunitária é a soberania do Direito e só nele o povo encontrará a suprema garantia de uma sua realização verdadeiramente democrática. Pois que esta realização será unicamente aquela em que se verifique um autêntico reconhecimento do homem pelo homem, em que todos e cada um sejam chamados a participar comunitariamente com o seu direito e a sua liberdade". $\left({ }^{32}\right)$

28 F. OSSENBÜHL, trad. cit., pág. 2101.

29 A. CASTANHEIRA NEVES, op. cit., pág. 229.

30 Idem, pág. 230.

31 Ary Florencio GUIMARÃES, "Liberdades fundamentais da pessoa humana em face do Estado", tese, nos "Anais do 1.0 Congresso Interamericano do Ministério Público", São Paulo, 1956, pág. 338, 2.0 velume.

32. A. CASTANHEIRA NEVES, op. cit., pág. 231. 
O que vem de ser dito explica o sentido mais profundo do princípio da separação de pcderes. Um mero Estado de legalidade contenta-se com a rígida obediência a uma discriminação de competências entre as esferas do Executivo, do Legislativo e do Judiciário. Retrata o Estado de direito formal. Uma concepção de Estado de Direito em sentido substancial ou material vai porém muito mais longe.

No que tange ao Judiciário, a exigência de magistrados realmente independentes para a realização autônoma do Direito radica na fundamental missão do Juiz na concreła realização histórica do Direito. O juiz, em sua tarefa de dizer o Direito, deve ser capaz de dizê-lo, se necessário, em contradição $\mathrm{ccm}$ as próprias razões de Estado, na defesa da pessoa. Ele há de ser um servidor do Homem muito mais que um servidor do Estado. Ao interpretar e aplicar o Direito, - juiz procurará realizar, no caso ccncreto, a intenção fundamental do Direito: a de tornar a vida humana, em todas as suas dimensões, mais capaz de realizar as finalidades do ser humano e da sociedade humana. O juiz, em face dos direitos do homem, não pode ser neutro.

Quanto ao Legislativo, a cclocação em suas mãos da possibilidade de modificação do Direito Positivo - sem delegações às tecnocracias - é fundamental: pois é o Poder mais diretamente vinculado ao povo, pela sua origem. Assim, a origem popular do Legislativo pelo voto direto e secreto destina-se a dar expressão (sem prejuízo de outras formas de manifestação de tal direito, fora da esfera parlamentar) ao "direito de participar ativamente da vida pública e de trazer assim a sua contribuição pessoal ao bem comum dos cidadãos", decorrência da dignidade da pessoa, como salienta João XXIII ( ${ }^{(33)}$.

A realização do Estado de Direito exige, portanto, um Judiciário independente e um Legislativo escolhido pelo povo. De fato, trata-se de um Estado que "implica a submissão do Estado-governo ao Estadosociedade, em lugar da subordinação deste a aquele", ao contrário do Estado absoluto, em que "o governante é o monopolizador do poder; o gcvernado, destinatário". ${ }^{(34)}$

O Estado de Direito é Estado subordinado ao Direito. A sociedade toda colabora na tarefa de realização do Direito. Este não se confunde com a vontade do Chefe, nem a do Presidente, nem a dos tecnocratas, nem a de um Grupo, nem a de um Partido.

Em um tal Estado, os direitos fundamentais da pessoa humana podem ser reconhecidos e tutelados. Só podem ser reconhecidos e

33 JOÃO XXIII, "Pacem in Terris", carta en é́clica, n. OS $_{S} 26$ e 73, in "As encíclicas sociais de João XXIII", edição da livraria Jcsé Olympio, Rio, 1963, 2.0 vo!., págs. 588 e 599.

34 Antonio HERNANDEZ GIL, "Metodologia de la Ciencia del Derecho", tomo III, Madrid, 1973, pág. 342 .

tutel

fund

come

do.

exist

apre

rocrä

4.

- $\mathrm{Br}$

de $\bar{c}$

Presi

um

de [

dade

dros

tritiv

meic

aglu

bipa

para

$\mathrm{ca}, \mathrm{a}$

o dir

na $c$

Cons

com

sinta

gistr

Estac

juízc

e $m_{i}$

o nc

nem

lidac

sagri

a cir

repr

fessc

confi

um

cessi 
tutelados em um tal Estado. Pois que no Estado de Direito, os direitos fundamentais da pessoa são "direitos de defesa contra o Estado" que, como tal, "têm algo a dizer, que é superior ao tempo, e sempre válido. Uma defesa contra o arbítrio será sempre necessária, sempre que existir o Poder; e isso é igualmente verdadeiro, quer o "Estado se apresente como monarca tirânico, como maioria tirânica ou como burocracia que se apoderou do Poder". $\left.{ }^{(35}\right)$

4. A realidade brasileira: especificação exemplif̊icałiva. Não vive - Brasil em um Estado de Direito. A rigcr, dado o permanente poder de alteração da Constituição e das leis ordinárias de que dispõe o Presidente da República, é de duvidar-se até mesmo que seja o nosso um Estado de legalidade. Mas é indiscutível que não é um Estado de Direito. Não tem o cidadão brasileiro ccmum qualquer possibilidade de influênica real na formação do Direito. Nem fora dos quadros parlamentares - pois aí está todo um conjunto de normas restritivas destinadas a dificultar todas as possibilidades de utilização dos meios de comunicação para o debate político, todas as tentativas de aglutinação de forças políticas fora do estretio leito de Procusto do bipartidarismo, a amedrcntar o estudante e a impedir-lhe a formação para a vida pública tradicionalmente exercitada na política acadêmica, a manter o trabalhador impedido de exercer em absoluta liberdade - direito de dirigir os organismos sindicais e de, através destes, influir na condução da política econômica e social do País. Nem através do Congresso, pois este vive sob a ameaça permanente das cassações e com um poder legislativo e constituinte que existem enquanto o consintam os titulares dos poderes absolutos emanados do Al-5. A magistratura não tem as tradicionais garantias. Vive $\circ$ Brasil em pleno Estado absclutista; esta é uma mera constatação, que independe de juízos de valor. O Estado-governo não se subordina ao Direito: produz e mantém o anti-Direito.

Em face de tudo o que anteriormente demonstramos, não sendo - nosso um Estado de Direito, daí decorre que não existe entre nós nem efetiva consagração nem efetiva tutela dos direitos da personalidade. Pouco importa tenha o texto da Carta outorgada em 1967 consagrado longa lista de direitos individuais e sociais: tudo isso reduz-se a cinzas com a simultânea vivência do Ato Institucional n. ${ }^{\circ} 5$. Este representa "o próprio cerne do regime", no expressivo dizer do professor Pinto Ferreira. $\left({ }^{36}\right)$. E, com efeito, são tão grandes os poderes conferidcs pelo Ato 5 ao Presidente da República que esse Ato forma um todo, inafastável em seus profundos malefícios por meras concessões setoriais, de todo ineficazes, pois a todo tempo retiráveis se 
não se exclui o próprio princípio do arbítrio e da onipotência do Executivo, que o Ato instituiu. Como disse, com extrema felicidade, o professor Josaphat Marinho: "Proclamar direitos e instituir garantias nos textos, para anulá-lcs na prática, sob a invocação permanente ou prolongada de razões de Estado, é forma larvada de exercitar a ditadura. Esse procedimento sinuoso intimida o indivíduo, mutilando-lhe a personalidade e a autonomia, e o deseduca, porque desperta nele a descrença no valor das leis". ${ }^{(37}$ )

As reflexões que acabam de ser feitas guardam íntima ccerência com as opções axiológicas anteriormente feitas: constituem análise crítica desenvolvida à luz de tais opções.

Se percorrêssemos analiticamente a "Declaração Universal dos Direitos Humanos" das Nações Unidas, seria longa a enumeração das incontáveis violações a esses direitos praticadas no Brasil em decorrência do tipo de ordem arbitrária vigente e da falta de uma adequada proteção à segurança jurídica do cidadão. A demonstração é feita de modo cabal por Heleno Cláudio Fragoso. ${ }^{(38)}$ Nós nos limitaremos para não incidirmos em repetição - à análise das violações do princípio da igualdade, consagrado pelos artigos I e VII da mencionada Declaração.

O princípio da igualdade é objeto de ampla análise por parte dos pesquisadores do "Centre de Philosophie du Droit de I'Université Libre de Bruxelles", e de um modo especial por parte de Ch. Perelman e Paul Foriers. Em tais trabalhos, foi desenvolvida importante distinção entre do is aspectos da igualdade: a igualdade perante a lei e a igualdade na lei. Se utilizarmos a síntese feita por Petzold, jurista venezuelano discípulo de Foriers e Perelman, essa distinção será tornada bastante clara. "A igualdade perante a lei responde à obrigação de aplicação das normas jurídicas gerais aos casos concretos, em conformidade com o que elas estabeleçam, ainda que daí resulte uma discriminação". Quanto à igualdade na lei, ela exige que a norma não contenha distinções fundadas em critérios que conflitem com as normas constitucionais, com a lei, com os costumes, ou com os princípios jurídiccs superiores ao direito positivo. Em decorrência, a "igualdade perante a lei é uma exigência feita a todos os que aplicam as normas jurídicas gerais aos casos concretos, enquanto que a igualdade na lei é uma exigência dirigida tanto aos que criam as normas jurídicas

36 PINTO FERREIRA, "Teoria Geral do Estado", 2.0 vol., Saraiva, São Paulo, 1975, pág. 755.

37 JOSAPHAT MARINHO, "Dos direitos humanos e suas garantias", in "As tendências atuais do Direito Público" - Estudos em homenagem ao professor AFONSO ARINOS, Forense, Rio, 1976, pág. 180.

38 Helene C'áudio FRAGOSO, "Direiło Penal e Direiłos Humanos", Forense, Rio, 1977, pág. 136 e seguintes. 
gerais quanto aos que as aplicam aos casos concretos". $\left({ }^{39}\right)$ No fundo, a distinção guarda paralelismo com a distinção entre as noções de Estado de direito e Estado de legalidade. Com efeito, a noção de igualdade perante a lei vincula o juiz mas não o legislador. O juiz poderá aplicar, sem qualquer quebra do princípio da isonomia, uma lei que, em si mesma, contenha inadmissíveis desigualdades entre seres humanos. Assim, o juiz do $3 .^{\circ}$ Reich que aplicasse a mesma norma restritiva a fodos os judeus não estaria vulnerando o princípio da igualdade perante a lei. $O$ que demonstra que a pessoa só é efetivamente protegida se o preceito da igualdade também vincula o legislador, sem prejuízo da vinculação do juiz: daí a importância fundamental da igualdade na lei.

Tal princípio, porém, ressalta ainda Pełzold, "não implica evidentemente a igualdade absoluta de todas as pessoas em face das normas jurídicas gerais - mas antes a ausência de discriminações baseadas sobre critérios de distinção proibidos pelo direito positivo ou por princípios superiores ao Direito positivo". E que, de modo aparentemente paradoxal, há por vezes, nas normas, certas desigualdades igualadoras. Elas buscam dar tradução concreta ao denominado princípio da igualização social: "trata-se de um princípio de compensação das desigualdades sociais, compensação realizável pela promoção das pessoas socialmente desfavorecidas, ou pela diminuição da riqueza e do poder daquelas que gozarn, ao contrário, de uma condição sccial favorável". $\left({ }^{40}\right)$ Sem tal princípio, seriam incompreensíveis algumas leis fiscais e, de um modo geral, o próprio caráter protetivo do trabalhador que tem o conjunto do Direito do Trabalho.

Assim, são claramente incompatíveis com um verdadeiro Estado de Direito as discriminações contrárias ao direito da personalidade em matéria de Direito do Trabalho, quer se fundem em motivos de crdem racial, quer se fundem sobre o sexo (de que é especificação a cláusula de celibato imposta à mulher que trabalha, ou a desigualdade de remuneração entre homem e mulher) quer se fundem, finalmente, sobre opiniões políticas ou ideológicas. $\left(^{41}\right)$ Desta última espécie são as regras, estabelecidas no serviço público brasileiro que, para ingresso ou promoção, embora nem sempre de modo confessado, levam em conta as posições políticas do servidor, conforme repetidas notícias veiculadas pelos jornais.

Tais discriminações ferem evidentemente o princípio da igualda-

39 Hermann PETZOLD, "Le principe de l'égalité devant la loi dans le droif de certains États d'Amérique Latine", in "L'Égalit-", vol. I, Bruylant, Bruxe!as, 1971, págs. 100 e 101.

40 Idem, pág. 147.

41 esquema básico encontra-se na "La discrimination em matère d'emplei et de profession dans les pays membres de la Communanté Économique Eurcpéeme", in Revue Internationale de Drcit comparé, pág. 9. 
de perante a lei. Quando decorrem de texto de lei, ferem, ainda assim, o princípio da igualdade na lei.

Um outro exemplo, em outra ordem de considerações, é o das normas jurídicas destinadas a, compensando desigualdades existentes no mundo dos fatos, darem atuações ao princípio da igualização social. Bom exemplo é o da problemática dos deficientes mentais e físicos. Nosso país ressente-se de total ausência de normas que assegurem adequadas oportunidades de formação e trabalho a essas pessoas, física cu mentalmente desfavorecidas. Neste particular, é exemplar o artigo 71 da nova Constituição portuguesa: "1 - Os cidadãos física ou mentalmente deficientes gozam plenamente dos direitos e estão sujeitos aos deveres consignados na Constituição, com ressalva do exercício ou do cumprimento daqueles para os quais se encontrem incapacitados. 2 - O Estado obriga-se a realizar uma política nacional de prevenção e de tratamento, reabilitação e integração dos deficientes, a desenvolver uma pedagogia que sensibilize a sociedade quanto aos deveres de respeito e solidariedade para com eles e a assumir o encargo de efetiva realização dos seus direitos, sem prejuízo dos direitos e deveres dos pais e tutores". Com tal norma, deu a Consitituição portuguesa cumprimento ao espírito e à intenção da "Declaração dos direitos do deficiente mental", promulgada pela Assemb!éia Geral das Nações Unidas, em 1971. A. legislação suíça é minuciosa na proteção aos deficientes, quer quanto à formação escolar especial, quer quanto à formação para o trabalho, quer quanto à obtenção do emprego, quer quanto à atividade em oficina protegida.

Vários países eurcpeus possuem leis obrigando os empregadores a reservar uma certa percentagem das vagas disponíveis para pessoas portadoras de deficiências. ${ }^{42}$ )

Mesmo no plano jurídico-penal, ocorrem violações nítidas ao princípio da igualdade, como demonstrou Heleno Cláudio Fragcso ao analisar a diferença de tratamento entre ricos e pobres quanto à contravenção de vadiagem e, de modo geral, no tratamento recebido do aparelho repressivo policial-judiciário. $\left({ }^{43}\right)$

O princípio da igualdade é ferido, em matéria que interessa de perto, quer ao Direito Privado, quer ao Público, em matéria de capacidade. Uma das grandes linhas de evolução do Direito Civil é a que se orienta no sentido de extinção de todas as barreiras que impeçam ainda a igualdade completa entre os hcmens quanto à capacidade de

42 "La condition juridique des handicapés mentaux", colóquio de 24 de abril de 1972, Georg, Genebra, 1972, págs. 28-29, 38, 43 e 63.

43 Heleno Cláudio FRAGOSO, "Advocacia: Igualdade e desigualdade na administração da justiça", in Anais da VI Conferência Nacional da Ordem dos Advogados do Brasil, Salvador, 1976, págs. 124-125. 
direito. Nesse sentido, é de referir-se a aguda observação do professor Orlando de Carvalho. O ilustre juri:ta poriuguês menciona as várias incapacidades que, criadas sem base em norma legislada, estabelecem "muros de ódio, repugnância, intolerância". São restrições, criadas pela vida, e que vedam ingresso em determinados lccais ou participação em determinadas atividades ou a fruição de bens da vida (inclusive de natureza cultural) e que se fundam em desigualdades econômicas, sociais, raciais, religiosas, ou políticas. $\left({ }^{44}\right)$ Mas o princípio da igualdade é também ferido em matéria de capacidade com base até mesmo em normas escritas no caso de margina!ização da vida pública dos chamadcs "cassados". E muito grave essa restrição tornada perpétua por pouco inspirada decisão dos tribunais - pois, criando verdadeira capitis diminutio, dividiu os cidadãos brasileiros em cidadãos de primeira e de segunda categoria.

Mais ainda: se nos detivermos agora no plano dos direitcs da personalidade tal como habitualmente catalogados nos Códigos Civis, facilmente nos convenceremos de como a ausência entre nós de um verdadeiro Estado de direitc faz com que inexista, no plano do concreto, a tutela de tais direitos.

Um exemplo, apenas: a proteção da inviolabilidade das comunicações telefônicas. Tanto a Constituição italiana como várias outras Constituições européias prevêem como únicas limitações possíveis à inviclabilidade de tais comunicações as determinadas pela autoridade judiciária, e de modo motivado. $\left({ }^{45}\right)$. Nessa linha de considerações, a Cour de Cassation francesa julgou inadmissível "a operação realizada, que tendia a obter, por surpresa e com violação do segredo das comunidades telefônicas, a constatação de uma infraçãc e a identificação de seu autor ainda desconhecido". $\left({ }^{46}\right)$ Seria útil contrastar essa jurisprudência com certos hábitos que se vêm fazendo sentir no Brasil.

Constitui ainda violação da intimidade da vida privada a atitude de órgãos policiais que, conforme constantes referências da imprensa, (vejam-se as prisões efetuadas pela Polícia Federal do Paraná no caso das escolas primárias), efetuam prisões ingressando na intimidade de uma família sem respeitar nem mesmo os imprevisíveis danos emocionais às crianças que presenciam a cena. Pouco importa o respeito à legalidade extrínseca (mandado de autoridade policial), já que é a juridicidade substancial que é ferida. Com efeito, do próprio artigo 12 da Declaração Universal dos Direitos do Homem decorre a vedação das interferências na vida privada e familiar.

44 Orlando de CARVAlHo, op. cit., págs. 19 e 20.

45 M.G. MOFFA, "Liberté des cemmunications et interceptions teléphoniques", in "Vie Priveé et droits de l'Homme", "Actes du Troisiène Colloque International sur la Convention Europ-ene des droits de l'Homme", Bruylant, Bruxelas, 1973, págs. 226-227.

46 Raymond LINDON, "Les droits de la personalité", Dalloz, Paris, 1974, pág. 91. 